\title{
RIGOR E INEFABILIDAD EN LA MÚSICA
}

\author{
Şerban-Dimitrie Soreanu
}

\author{
Universidad de Música (Bucarest)
}

En el siglo xx, los signos se multiplican de forma fabulosa, se diversifican hasta lo incognoscible, las significaciones restringen su área de resonancia, se particularizan a niveles infinitesimales; los significados no mantienen un rumbo establecido, como si tuvieran finalidad alguna, se vuelven confusos. Los signos son difíciles de «leer», las significaciones se «esconden» en los detalles, el sentido se «esparce» hacia la nada del desequilibrio inútil, no emocional. Son textos («signos») en los que una melodía elucubrante recibe, sin ton ni son, significación interpretativa, al lado de otros «modelos textuales» en los que los diseños nobles, lógicos y expresivos se disipan en deterioraciones incapaces de modelación; por encima de todo está la pregunta «qué» en «cómo» sin ton ni son, sin «sentido». Los lenguajes tratan de organizar lo que ya no puede ser sostenido, por la enorme tendencia de «otra cosa» y de «de otro modo». En la música, parece ser que se ha alcanzado ya el nivel último de las disoluciones, tanto por el rehacer caótico de los trayectos antaño excelsos, como por la invención de unas expresiones inexpresivas (?!). No se deben dramatizar los «fines» (los 
límites) de un fenómeno; nada más deprimente que acumular sin finalidad, y el «sentido» óptimo podría ser la resurrección continua. En el fondo, la muerte forma parte de la vida. El fenómeno sonoro es, sin embargo, por definición, muy fuerte: tiene un modelo a priori, existe por medio de la vibración sensible y resiste por medio de la resonancia; de este modo («coloquial») era —es- será en función de: asignación, consignación, designación [sic]. Así pues, una posible cercana recuperación de los lenguajes musicales no resulta del todo mala. Los textos empezarían el trámite explícito de la idea hacia su moral, las interpretaciones producirían energías auténticas, y las finalidades se verían alcanzadas.

Dicho de otra manera, el conjunto está severamente condicionado por el equilibrio real, demostrable, de las partes componentes; en realidad, en el universo «musical» todos crean. El signo de la partitura es evaluado sonoramente, se le da lo que puede entender el espíritu humano: candor, color, imagen. Después de la «emisión», queda un eco, una reflexión, una resonancia, una reacción (por lo general) complementaria. Los creadores de «texto» han empujado algunas veces de forma aberrante, otras veces de forma fantasiosa (en busca de mundos sonoros, y no sólo virtuales), los límites de los lenguajes tanto en la notación propiamente dicha, como en la «magia» posible (incluso si a veces es improbable) de las reverberaciones, de las combinaciones acústicas entre el modelo sonorizado en circunstancias determinadas (la casuistica de tipo físico: sala, instrumentos) y la percepción subjetiva del estándar cultural. La notación del siglo pasado ha recorrido espacios extensos desde el aumento de las designaciones anteriores (especialmente a través de términos linguísticos) hasta inventar unas consignaciones sugestivas (que necesitaban leyendas explicativas, raras veces generalmente válidas).

Los intérpretes, a su vez, han dado una significación no solamente a los signos (que, por muy explícitos o incluso imperativos que fuesen, no son en realidad más que pre-textos), sino también a su impresión sobre aquellos «signos»; las impresiones podían ser radicalmente diversas, o sólo (...) concesivas.

Como consecuencia de la participación activa, implicada de los músicos de «producción», las significaciones de los modelos textuales «creados» se multiplican (probablemente) en progresiones geométricas; los estilos demuestran sus raíces estrictamente humanas, personales. Algunos intérpretes parecen no evaluar «correctamente» el texto, teniendo un solo objetivo: gustar, ser diferentes de sus antecesores. 
Escuchando hoy un nombre famoso antaño, comprendemos las fuentes y los recursos que habrá tenido en la restitución sonora de un texto; por una parte funciona de forma perpetua un fluido general de «vida aplicada» (no «fundamental») al nivel de las aspiraciones, por otra parte se impone en cualquier momento y en cualquier lugar el estándar de los instrumentos y de las salas de concierto. Otros intérpretes significan «los textos» a nivel estrictamente enunciativo, aumentando, a su vez, el número de los modelos sonoros por la comprensión restringida de lo «estrictamente necesario», tan diferente de uno a otro. Aquí convendría establecer (¿por parte de quién?) una especie de tablas sinópticas de «importancias»: en ciertas situaciones, los criterios axiológicos son, más que productores de contrariedad, contradictorios.

Una posible «verdad» de la creación interpretativa podría ser revelada por la significación del camino entre un sonido y otro, por encima de la emisión «en sí» de cada uno en parte. Es más: «el silencio» en la música tiene una expresividad comparable a la vibración sensible (el sonido propiamente dicho); antes de poner en evidencia las armónicas de un sonido tiene lugar su preparación, y los silencios entre los sonidos pueden ser decisivos en el discurso, teniendo o un papel de redundancia, o un papel de antítesis, en la perspectiva de la realización «del acto interpretativo». «El Fondo»y «el Hecho», los modelos «textual»e «interpretativo», los determinantes «creadores» completan los símbolos artísticos en experimentos interdependientes; de hecho todos los nombres importantes de la «música» han tenido acceso directo al «fenómeno» sonoro a través del conocimiento completo de los lenguajes (del sonido y de la pausa, como altura-vibración - armónica y como duración - proporcional, hasta las relaciones sutiles de fraseo, dinámica matizada y movimiento expresivo-motivado) y de las imágenes plausibles que pueden generar las arquitecturas sonoras. La relación entre los sonidos es «la clave» del arte musical, lúcidamente corroborada con la vida misma por la sin-fonización [jsic!] de los estados, de los acontecimientos, de las voluntades, de las posibilidades, de las creencias.

Desafortunadamente, hay también creadores de lenguajes confusos; compositores que subevalúan la expresión sonora e intérpretes que subestiman la escritura. Algunos se esconden detrás de unos esbozos utópicos, voluntariamente atípicos [isic!], ostensivamente vanguardistas; otros exhiben sus destrezas ignorando las prerrogativas textuales.

Los límites del diletantismo enmascarado a la hora de adoptar renovaciones se confunden a veces con las transfiguraciones altamente 
profesionales; afortunadamente, el principio de la «intuición» ofrece grandes recursos para poner las creaciones en «su lugar». Al fin y al cabo, a cada uno (si se le conoce) se le da lo que se merece; dicho de otra forma, el arte musical es (?) el más generoso en «significaciones», gracias a su ultra-conocida «abstracción». Por lo tanto, cada uno oye lo que quiere, sabe, comprende, cree o necesita.

«La significación» en música es literalmente infinita (aunque los hombres no sepan - ¿todavía? - qué es «lo infinito»), la audición realizándose según reglas estrictamente individuales, o mejor aún, particulares.

Los creadores de «texto» y de «interpretación» han imaginado mundos expresivos virtuales, en perfecto dominio de la suma de virtuosidades potenciales, primero latentes, sonorizados ulteriormente con la finalidad declarada de «gustar». La música ha nacido como un juego del alma que tiene mente y voz para «cantar»; en un momento u otro de nuestro carácter cambiante, los límites de las reglas se habrán adaptado a la «recepción» natural. Algunos (como en cualquier otro destino humano) habrán hecho menos de lo suficiente o, todo lo contrario, demasiado; así algunos modelos textuales y / o interpretativos han desaparecido. Otros, esenciales para la civilización humana, han hecho exactamente lo que «debían» hacer: técnica (es decir «artísticamente») y expresivamente (óptimamente promovido), de tal manera que «los receptores» estén, ¿como no?, encantados.

La elucidación de las «partituras» no es una operación acabada una vez que se haya «recorrido». Hay dos motivos: la latencia «de la concepción» y la explicitación «de las resonancias». El sonido musical tiene en su composición estas dos «intensidades». El texto organizado permite innumerables modalidades de expresión (del nivel definido del instrumento, hasta el nivel técnico del intérprete, para no hablar de las variantes de timbre de realización y / o de transcripción) y todavía más percepciones de emociones estéticas (a veces incluso físicas, subjetivas).

Los sentidos han sido bloqueados a menudo en dogmas de «recepción», pero -igracias a Dios! — el movimiento propio del discurso musical ha impuesto beneficiosamente reacciones, actitudes vivas de evaluación de los efectos sonoros, arquetípicas en un "principio», ampliamente civilizadores en «la continuidad». De un instante aislado, íntimo, de relajación, «el receptor» de música construye su propio universo, que se vuelve continuo (evidentemente, donde la sociedad 
humana lo toma en serio), necesario, vital. Mirar y escuchar selectivamente hacen que se disciernan los valores artísticos; «el receptor» toma en serio tanto la manera en la que se le ofrece la expresión sonora, como los efectos acústicos propiamente dichos. La imagen y la sonorización no adecuadas pueden producir traumas de la percepción estética, y hacen poco creíble el trayecto perseguido.

Hay un riesgo mayor que se perfila en la esquematización del «producto», hasta el nivel de la no identidad, debido a una multiplicación de «serie» de las fórmulas de transformación en sonido, del signo gráfico; otro riesgo se insinúa en la aglomeración de «indiferencias» frente a los elementos de construcción sonora, «cualquier cosa» convirtiéndose en «de cualquier manera». Asimismo, a veces, «la interpretación» se expone exageradamente, ostentando el inefable «buen sentido». El riesgo fundamental es la soberbia autoidentificación sin más, con la letra y el espíritu codificados en el texto, que se atribuyen los diletantes, con la esperanza de que «de ningún modo» sea «de algún modo». Casi a lo largo de toda la recepción, el que escucha tiene que elegir entre las sensaciones sin reglas, momentáneas, y las vivencias complejas, transfiguradas. Para un «receptor» de cualquier otro constituyente artístico del espíritu creador-estético, digo con el temor de no contrariar, es más... cómodo. En un cuadro, aunque sea no figurativo, en una poesía, aunque sea muy hermética, se pueden encontrar similitudes con la vida de cualquiera. Vuelvo por lo tanto a la así llamada «abstracción» del lenguaje musical; por un lado, la construcción de «texto» (sistemas de entonación, rítmicos, formalizantes), por otro lado, las técnicas instrumentales o vocales (la problemática variada según las conjeturas de la relación sala-público) provocan cierto estado de perplejidad. En la música, no existen las palabras del habla corriente, ni siquiera en la canción con texto literario, para que sean posibles «los equivalentes» corrientes, usuales. Es más: en función del estado psíquico, de la cultura y de un (casi) imposible de confesar «instante de gracia», todos crean imponderables, únicas «transfiguraciones»: el compositor de la «idea», el dibujo codificado en la partitura; el intérprete del «texto», la descodificación con el instrumento; el que escucha de la «escucha», el reconocimiento de las propias imágenes.

Las indicaciones de «texto» son interpretables, discutibles, desde la perspectiva histórico-estilística y del enfrentamiento con los imperativos del momento; muchas de las obras de primer rango de la cultura musical han tenido vidas agitadas; desde la adoración hasta el repudio. Las 
interpretaciones de escena o de almacenamiento fónico, en una casi general selección, han conocido la grandeza y la decadencia. El público, compuesto por amantes incondicionales de la música y por cazadores de efectos, construye sin cesar mitos, a veces con la ilusión de un mundo mejor, otras veces sobre ruinas de templos que se han quedado sin ídolos. De una pintura nos mira un «retrato»; en una música, un «tema» nos ofrece una sugerencia de imagen. De una prosa se desprende un fragmento de «existencia»; en una música un «discurso» reúne lo temporal (las pulsaciones rítmicas) con lo espacial (las resonancias).

Por lo tanto, la libertad inmensa de la «música» puede inhibir (¿qué será esto?), al igual que puede estimular energías superiores (una estructura sonora puede ser exacta, moral, bella). Energías, llamadas «rigor e inefabilidad», ;sin las cuales estamos perdidos!

Existen, sin duda, geometrías impecables: el círculo, el rectángulo, el triángulo equilátero. Al parecer, aquí está la «duda», geometrías (sonoras, y no solamente) sometidas al «error». Parece que ningún arte, con la feliz excepción de la música (!!!), ha ofendido a la perfección: cualquiera comprende que algo «erróneo» no tiene sentido, provocando incluso rechazo. La música ha impuesto «desviaciones» continuas de los lenguajes caídos rápidamente en lo efímero, en lo incompleto; hoy, con grandes esfuerzos podemos aceptar «productos» sonoros de los días de «ayer», mientras rostros de antaño imaginados picturalmente, esculturalmente, literariamente, parecen eternamente presentes. Sin embargo, las benéficas modificaciones de actitud de expresión musical no alteran el (¿usado?) sintagma: lo eternamente humano. Están presentes los principios de organización de «lenguajes» de los valores con los que hemos sido dotados a la hora de nacer: el ámbito auditivo de las armónicas perceptibles, el proceso binario de la respiración fisiológica, la sensibilidad emocional de las diferencias de intensidad. Todas estas «categorías» reúnen las artes, en espíritu universal; y son las mismas las que forman el «topos» explorable de las perpetuas modelaciones de «alturas», «duraciones», «frases», «timbres». Algunas búsquedas son «ejemplares» (únicas, irrepetibles); otras son «modeladoras» (únicas, estimulantes expresivamente). A veces, llega el momento de la «verdad», cuando Alguien —en especial- encuentra «la solución», el silencio del punto final...

Los mayores problemas a la hora de descifrar el lenguaje musical se crean por los «infra-signos». Éstos tienen simultáneamente dos actitudes paradójicas: cierran y abren capacidades de expresión (por escrito y en la interpretación) y de comprensión (en la recepción subjetiva). 
Por una parte, el creador de «texto»... desearía iniciar, proyectar, campos sonoros resonantes y claros, por otra parte se esconde en una sensible intimidad, sólo por él intuida sonoramente, gracias a y por culpa de las insuficiencias fatales de una notación limitada a proposiciones convencionales: ¿cómo de «fuerte» resulta un «forte» de «entusiasmo» en comparación con uno de «desesperación»?, y ¿qué genera el soporte de una característica y el de la otra? A su vez, el creador de «interpretación»... espera figurar construcciones sonoras plausibles, que se parezcan a los niveles elementales bio-energéticos (como la respiración, la sensación de bienestar, de calma, de melancolía y otras por el estilo), que aseguren el confort de la percepción razonable.

Por fin, el que escucha no es (desde la perspectiva de los inframódulos) demasiado... obediente; oye y comprende lo que quiere oír y necesita asegurarse momentos de vida personal. Todos juntos conspiran en un juego más bien egoísta, con manierismos frágiles: el compositor «quisiera», el intérprete «espera», el que escucha se adora a sí mismo. Casi nada se queda fuera de la «regla», pero — aquél-algo se vuelve «esencial»; el código del lenguaje tiene virtudes en la zona de «la libre circulación» de valores expresivos. En la «escuela» se aprenden los signos estrictamente necesarios para el acceso al universo plenamente artístico; la confirmación de la entrada es dada, con suerte, en el camino entre los espíritus: «texto-interpretación-recepción» como una especie de árbol de la vida con «raíz-tronco-fruto».

Todo «signo» sostenido por un «infra-signo» necesita el equilibrio entre el conocimiento de la «significación» y el don de una «ultra-significación» transfigurada interpretativamente, para emitir por resonancia un «sentido» normal e inocular mágicamente un «meta-sentido» civilizador, por razones culturales de relación necesaria de la «forma de ser» con «el tesoro» de la existencia de cada uno en parte.

Si sobre los «límites» podemos decir mucho (sobre el eje de las hipótesis) y en la esfera de la música, siguiendo esquemas verificados por el buen sentido y/o leyes científicas de la vida diaria, sobre «núcleos» energéticos sonoramente no gozaremos muy pronto (si va a ser aún lo que creemos que es la vida sobre la Tierra») de la alegría (?) de definir «los arquetipos» del lenguaje tan cargado, tan sencillo, tan confuso, $\tan$ directo, $\tan$ sutil, $\tan$ libre, $\tan$ restrictivo, $\tan .$. de todas las formas y ritmos nacidos de la imaginación de nuestros coetáneos.

Ésta es una variante del interior del fenómeno, de un lugar y tiempo configurados personalmente. La otra (u otras suposiciones) sería(n) una 
radicalización brutal del bien del mal. «La verdad» genuina y la «consecuencia» definitiva son, aquí y ahora, faltas de «signos», de «significaciones» y, sobre todo, de «sentido»; quedan todavía bastantes vías de búsqueda y sentiría mucho si alguien tuviera la soberbia de hallar la primera causa y el último efecto. La humildad terrestre de las búsquedas nos puede traer, todavía, grandes revelaciones de identificación, de autoconocimiento; el espacio musical es literalmente generoso: la escritura, la interpretación y la escucha son las más libres en cuanto a notación, presentación y puesta de manifiesto de una reacción.

Todo ello es «lo natural» y «el tesoro» de la música.

La música, en todo su eje existencial, es una cuestión de vida; hace preguntas y contesta a los constituyentes vitales bio-rítmicos, bioarmónicos y bio-lineares. En cualquier momento de nuestra vida relacionamos valores de duración, los proporcionamos, los soportamos, los reconfiguramos sin cesar. En los mismos momentos percibimos armonías de los sones que nos rodean y las evaluamos como consonantes o disonantes, dejándolas que nos confieran estados de bienestar o de malestar. Por último, realmente "por último», la línea de la vida, la historia, los caminos que recorremos, son filas de sonidos ascendentes o descendentes, melodías basadas en prototipos de intervalo de nuestro simple y esencial pensamiento y sentir binario. 